\title{
An Ecological Study of the Relationship between High Birthweight and Maternal Socioeconomic Indicators among US States
}

\author{
Louay Khir $^{1}$ \& Raywat Deonandan ${ }^{2}$ \\ ${ }^{1}$ Faculty of Medicine, McGill University, Montreal, Canada \\ ${ }^{2}$ Interdisciplinary School of Health Sciences, University of Ottawa, Ottawa, Canada \\ Correspondence: Raywat Deonandan, Interdisciplinary School of Health Sciences, University of Ottawa, Ottawa, \\ ON., K1N 6N5, Canada. Tel: 1-613-562-5800. E-mail: ray@deonandan.com
}

Received: July 26, 2016 Accepted: August 15, 2016 Online Published: February 21, 2017

doi:10.5539/gjhs.v9n4p91

URL: https://doi.org/10.5539/gjhs.v9n4p91

\begin{abstract}
Background: While low birthweight babies are widely recognized as clinically challenging, large for gestational age (LGA) births also pose medical risks. To better understand and address the rise in LGA births in the USA, a better understanding of its population health determinants is indicated.
\end{abstract}

Objective: We aimed to measure associations between incidence rates of LGA births and (1) trends in maternal health insurance rates and (2) per capita state healthcare spending rates in US states.

Methods: Using public data from the CDC's Wide-ranging Online Data for Epidemiologic Research (WONDER) online natality database, the Current Population Survey of the United States Census Bureau, and the Centers for Medicare and Medicaid Services, we computed Pierson's correlation coefficient for rates of LGA births, the percentage of women without healthcare insurance, and state-level governmental spending on health care, across 50 states and the District of Columbia.

Results: There is substantial correlation between rates LGA incidence and the proportion of insured women in a state $\left(r^{2}=0.47\right)$ and moderate correlation with the extent of governmental healthcare spending $\left(r^{2}=0.17\right)$.

Keywords: ecological study, high birthweight, maternal socioeconomic indicators, US States

\section{Introduction}

High birthweight (HBW) births, also called large for gestational age (LGA) births, are defined as those with birthweight of $4,000 \mathrm{~g}$ or higher, regardless of gestational age. In the USA, HBW births have become increasingly prevalent in recent decades, reaching up to $10 \%$ of total births (Martin et al., 2009). HBW is known to be associated with detrimental health outcomes, both in infancy and later. Short-term consequences of HBW are predominantly birth complications and higher rates of neonatal deaths, a truth that is of deep relevance to US public health, as that country has the highest rate of first-day infant mortality of all industrialized nations (Wilcox \& Russell, 1983; Save The Children, 2013). Some have proposed associations between HBW and an increased predisposition to the development of obesity, type 2 diabetes, risk of both childhood and adult malignancies, reduced cognitive development and health capital in childhood, reduced educational attainment, and worse labor market and health outcomes in adulthood (Baso et al., 2006; Savona-Ventura, Chircop 2003; Li et al., 2006).

Most research into the relationship between birthweight and societal policy has focused on the effects and prevention of low birthweight (LBW) (Johnson \& Schloeni, 2007), with HBW largely ignored (Khir \& Deonandan, 2014). Though the medical causes of HBW are becoming increasingly better documented, there is a gap in literature as to the non-biological causes, particularly those associated with maternal socioeconomic status (SES), which can profoundly affect infant well-being. An important factor affecting maternal SES is access to healthcare services, which is largely influenced by maternal health insurance status. Low income, manifesting as limited health care when health insurance is lacking, is well associated with access to prenatal care (Black et al., 2005), which is known to have a protective role against delivering a LBW infant. (Lu et al., 2003; Li et al., 2006) However, little is known of the relationship between prenatal care and the chances of delivering an HBW baby.

Access to healthcare, and thus to prenatal care, is also affected by overall state per capita healthcare expenditure. Positive infant health outcomes related to decreased LBW deliveries have been achieved through reducing 
financial access barriers to prenatal care (Lu et al., 2003; Reichman \& Florio, 2006). Data pertaining to healthcare expenditure levels, or other socioeconomic factors, and their effects on rates of HBW births, however, have not been reported. This study thus aims to measure associations between incidence rates of LGA births and (1) trends in maternal health insurance rates and (2) per capita state healthcare spending rates in US states.

\section{Methods}

Natality data for this analysis were drawn from the Center for Disease Control's (CDC) online web portal of information resources: Wide-ranging Online Data for Epidemiologic Research (WONDER). Data on health insurance rates were collected from the Annual Social \& Economic Supplement of the Current Population Survey (CPS ASEC) of the United States Census Bureau. Healthcare expenditure data were extracted from the Centers for Medicare and Medicaid Services (CMS). We examined trends based upon all births, for 50 states and the District of Columbia in each year of study. While primary analysis was conducted for the year 2010 (the most recent year for which full data were available), trends were confirmed in each previous year going back to 2002 .

The CDC WONDER natality online database, which reports counts of live births occurring within the US, was used to determine natality trends of all births, in all states, for each year of focus. Birthweight percentages were determined by comparing births per weight category, per state, to total births per state. High birthweight (HBW) births was defined as those greater than 4,000 grams, average birthweight as 2,500-4,000 g, low birthweight as 2,500 g-1,500 g, and very low birthweight as less than 1,5000 g, all regardless of gestational age.

Healthcare expenditure data incorporate all privately and publicly funded personal health care services and products (hospital care, physician services, nursing home care, prescription drugs, etc.). Hospital spending is included and reflects the total net revenue (gross charges less contractual adjustments, bad debts, and charity care). Costs, such as insurance program administration, research, and construction expenses, are not included in this total.

All data were ranked in descending order based on percentage of select birthweight categories per state. Corresponding data on health uninsurance rates and healthcare expenditure were left unranked. Statistical analysis consisted of the computation of Pearson's correlation coefficient, comparing the trends of LGA births across states to trends in healthcare spending and uninsurance rates. For comparison purposes, correlations were also computed for small for gestational age (SGA) births.

\section{Results}

All correlation coefficients were statistically significant $(p<0.05)$. The linear relationship between the incidence rates of LGA births and US state is shown in Figure 1 in comparison to the prevalence of uninsured women in those states. The trend lines are divergent, showing that states with high rates of LGA births tend to be those with low insurance rates. The square of the correlation coefficient $\left(r^{2}\right)$ for this relationship is 0.39 , with the highest value measured for the year 2006, for which the $\mathrm{r}^{2}$ was 0.47 . 


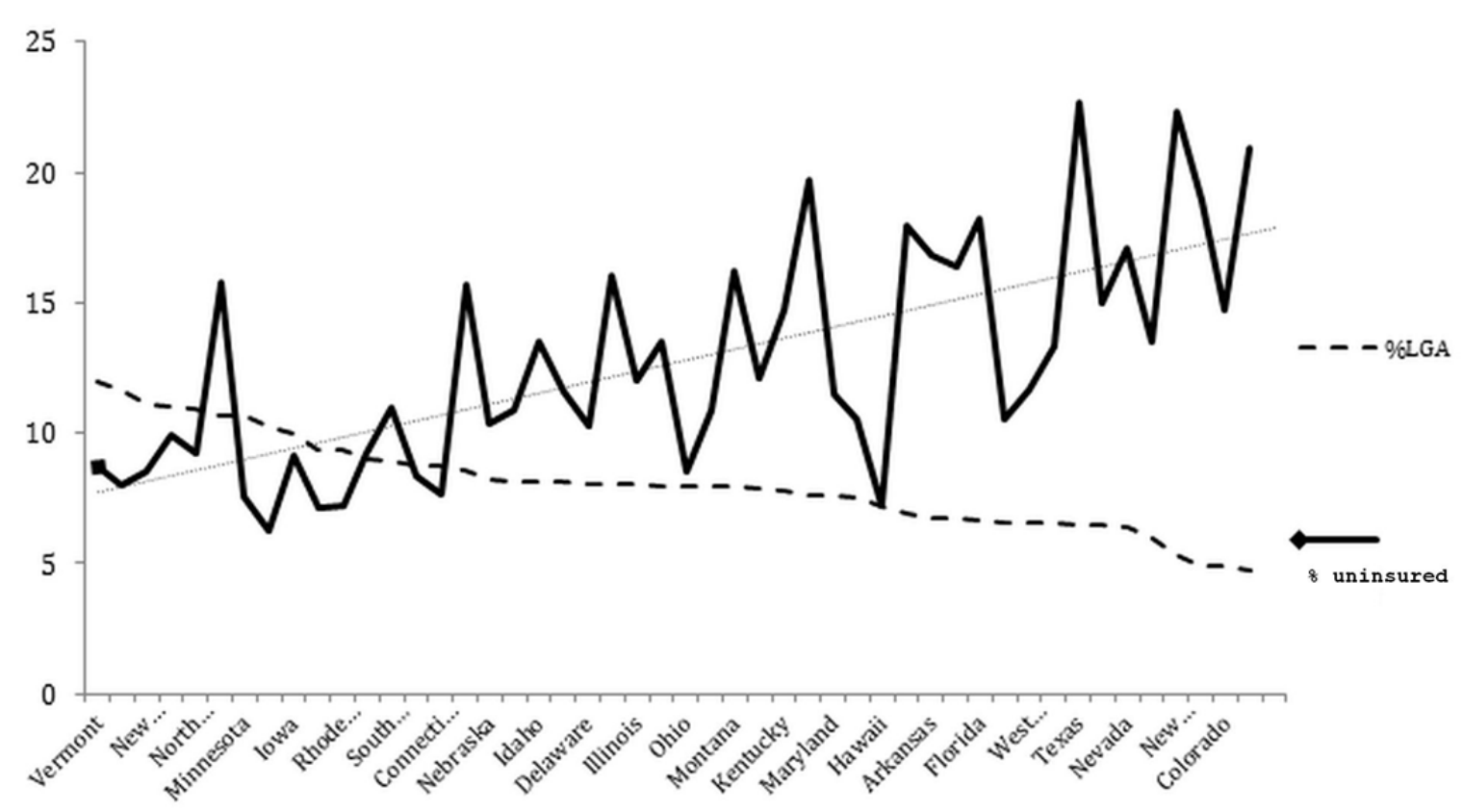

Figure 1. Incidence rates of large-for-gestational age (LGA) births and percentages of women without health insurance by US state, $2010, \mathrm{r}^{2}=0.39$

Figure 2, meanwhile shows the ecological relationship between the incidence rate of LGA births and the extent of state-level government spending on health care. As the latter does not change appreciably from state to state, there is no apparent correlation with LGA birthrates, with an $\mathrm{r}^{2}$ of 0.17 .

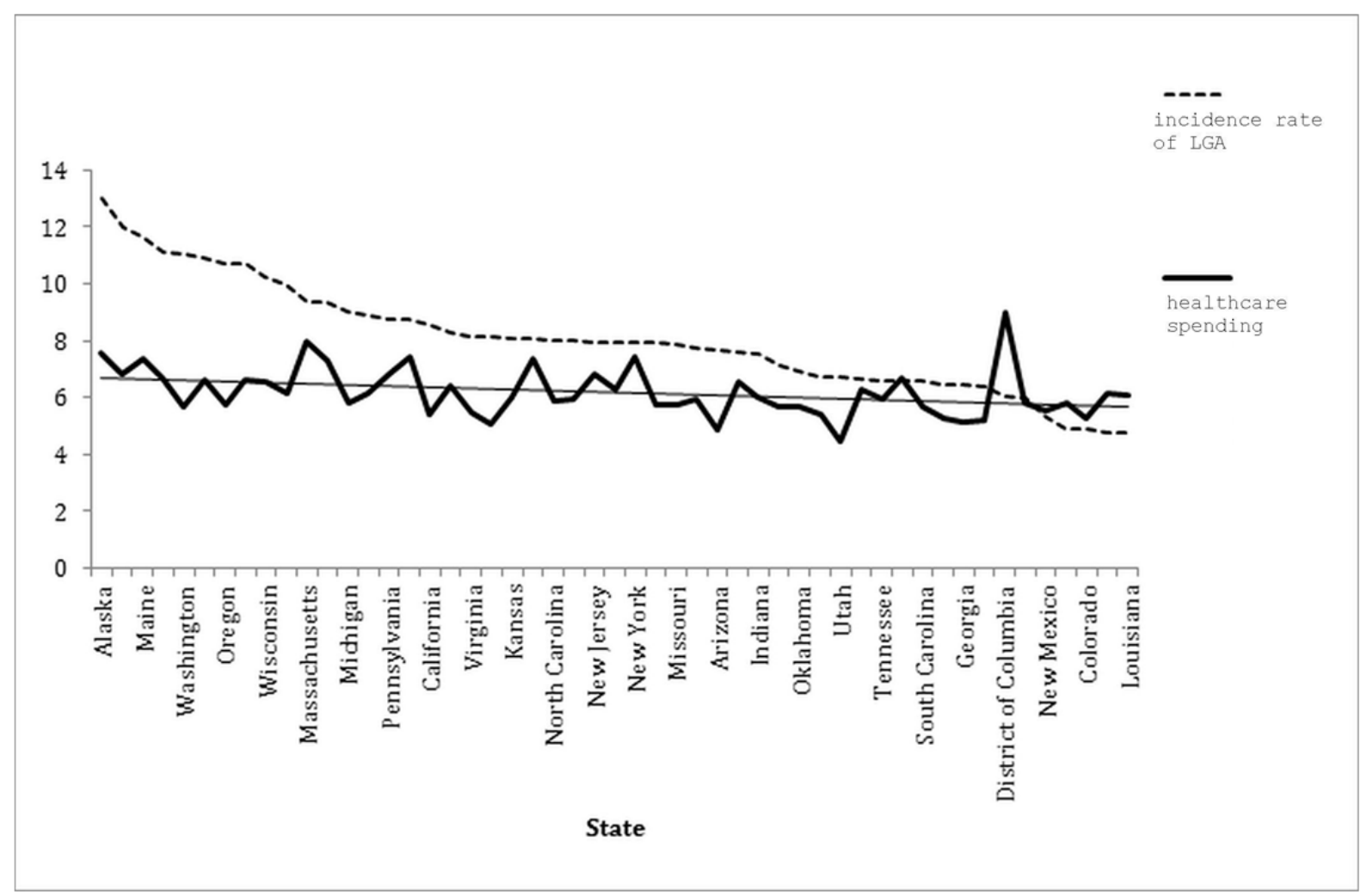

Figure 2. Incidence rates of large-for-gestational age (LGA) births and state-level government spending on health care (in increments of $\$ 10,000$ ) by US state, $2010, \mathrm{r}^{2}=0.17$ 
In contrast, Figure 3 depicts the comparison of SGA birth incidence with state-level uninsurance rates, showing that the two phenomena are neither divergent nor convergent, which suggests that SGA rates vary directly with uninsurance rates, with an $\mathrm{r}^{2}$ of 0.08 .

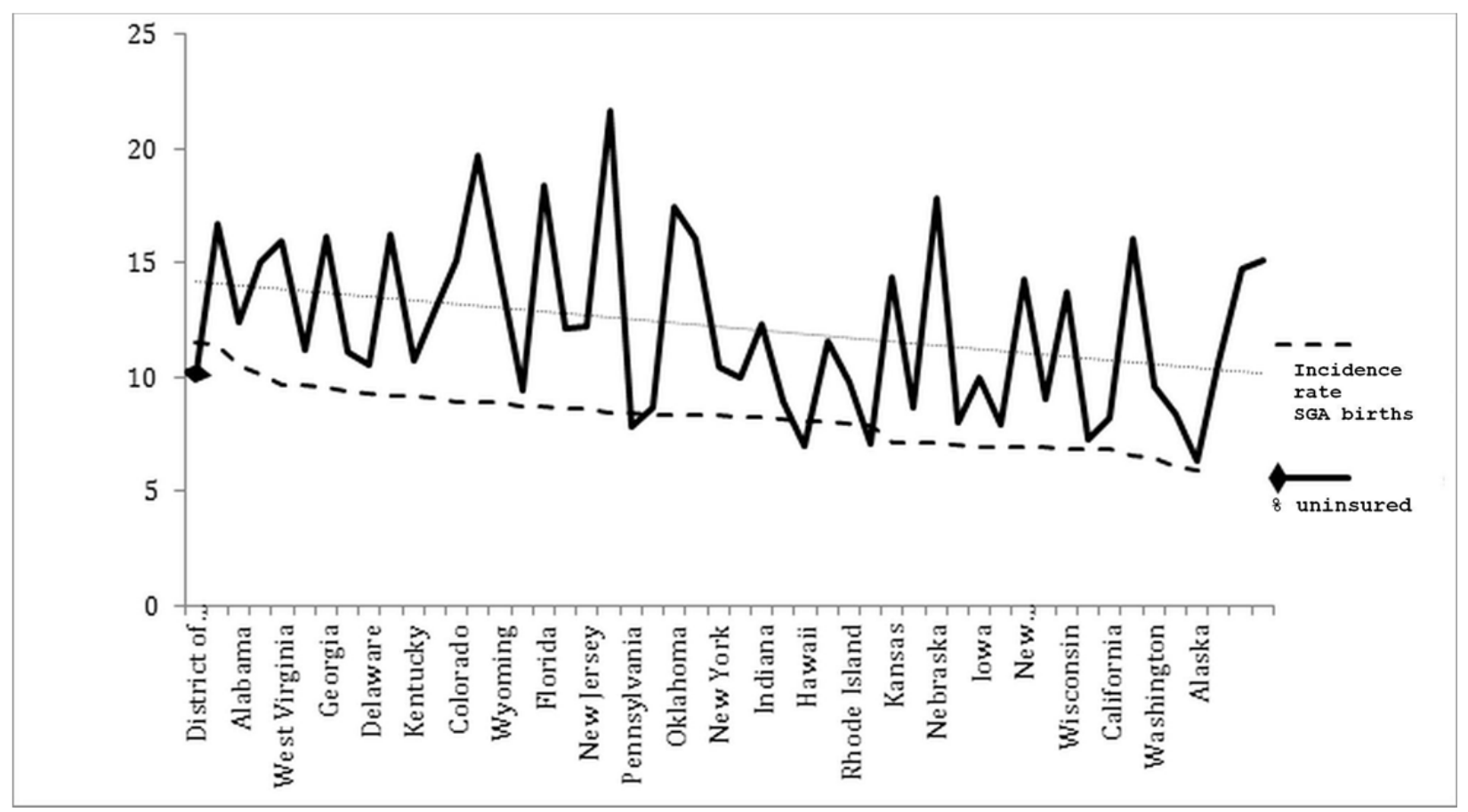

Figure 3. Incidence rates of small-for-gestational age (SGA) births and percentages of women without health insurance by US state, $2010, \mathrm{r}^{2}$ of 0.08

\section{Discussion}

Across all the years analyzed (2002-2010), we found consistent associations between lower rates of high birthweight infants in states with lower female health insurance rates. We also found that the rates of LGA births are largely unrelated to per capita state healthcare spending. The increase in percentage of HBW births per state, related to increased female health insurance rates, appears to also outpace the observed decrease in LBW births correlated with higher rates of insured females. This may suggest that prenatal programs that are geared towards the prevention of preterm births, and thus the delivery of LBW infants, may have the unintended consequence of raising overall birthweight and incidence of macrosomia, rather than solely targeting expectant mothers deemed at risk for delivering a LBW infant. This is purely speculation, of course.

The greatest limitation to this study is its ecological nature, which obviates the opportunity to make conclusions about individual experiences. Thus, any insights gleaned herein can be best used to formulate future research questions for studies focusing on individual experiences and the outcomes of specific programs. Given that caveat, our findings suggest an avenue for addressing birthweight trends through improving the social determinants of health, specifically access to healthcare services like prenatal care via state expenditures.

Over the past 20 years, prenatal care has been considered the greatest public health strategy for preventing low birthweight (LBW) births (Spencer et al., 1999). It has been noted, however, that when comprehensive, multicomponent prenatal care is offered to undifferentiated populations of high-risk pregnant women, it has not been shown to reduce LBW rates. Rather, the common practice of indiscriminately allocating interventions to populations of pregnant women who are deemed to be at risk for low birthweight, due to SES status, appears to mask (or at least dilute) the potential benefit of these interventions, thus increasing the likelihood that a proportion of the target population receives unneeded (and hence inappropriate) interventions, which in turn, decrease the probability that the intervention will significantly reduce the LBW rate at the population level (Liu, 1998; Stevens-Simons \& Orleans, 2009).

Therefore, a consequence of this practice may be an increased incidence of macrosomia in women deemed at risk of delivering a LBW infant. This is noteworthy as there is currently a lack of reliable diagnostic means for 
detecting macrosomia before birth; clinical and ultrasound estimates are of limited reliability, with studies suggesting that when birthweight exceeds 4,500 grams, only $50 \%$ of fetuses weighed within $10 \%$ of the ultrasound estimate (Melamed et al., 2011). Together, these factors may hinder the ability for early detection of women who are at risk for delivering an HBW infant, and subsequently may increase the probability that an inappropriate prenatal care regimen may be administered to these women.

Our finding that rates of HBW are unaffected by per capita state healthcare spending are consistent with other data that suggest a lack of beneficial health outcomes in countries with higher healthcare spending. The US has the highest per capita healthcare expenditure among peer countries, yet it fares poorly on life expectancy, infant mortality, premature mortality, and, of relevance to this study, early infant mortality (Wilcox \& Russell, 1983). In essence, it may not be the amount of money spent that is important, but rather how that money is targeted and spent.

These results are not conclusive, but rather are the beginning of wisdom. Further research should explore the link between state health spending and accessibility to prenatal care, and the extent to which that care underserves women at risk for HBW births. This has become more relevant, as the Affordable Care Act of 2010 mandates all insurance companies to cover prenatal visits, thus substantially increasing and easing access to all pregnant women, regardless of socioeconomic status. Any changes to the Act made by the new Presidential administration will necessarily affect the disposition of prenatal care, and thus the scope of funding effects on both LBW and HBW incidence.

\section{Competing Interests Statement}

The authors declare that there is no conflict of interests regarding the publication of this paper.

\section{References}

Basso, O., Wilcox, A. J., \& Weinberg, C. R. (2006). Birthweight and mortality: Causality or confounding? American Journal of Epidemiology, 164(4), 303-311. https://doi.org/10.1093/aje/kwj237

Black, S. E., Devereux, P. J., \& Salvanes, K. (2005). From the cradle to the labor market? The effect of birthweight on adult outcomes (No. w11796). National Bureau of Economic Research.

Khir, L., \& Deonandan, R. (2014). Shifting the birthweight paradigm. Health Science Enquiry, 5(1), 109-110.

Johnson, R. C., \& Schoeni, R. F. (2011). The influence of early-life events on human capital, health status, and labor market outcomes over the life course. The BE journal of economic Analysis \& Policy, 11(3). https://doi.org/10.2202/1935-1682.2521

Li, X., Zhou, L., Feng, Y. H., Abdul-Karim, F. W., \& Gorodeski, G. I. (2006). The P2X7 receptor: a novel biomarker of uterine epithelial cancers. Cancer Epidemiology Biomarkers \& Prevention, 15(10), 1906-1913. https://doi.org/10.1158/1055-9965.EPI-06-0407

Liu, G. G. (1998). Birth outcomes and the effectiveness of prenatal care. Health Services Research, 32(6), 805.

Lu, M. C., Tache, V., Alexander, G. R., Kotelchuck, M., \& Halfon, N. (2003). Preventing low birthweight: Is prenatal care the answer? The Journal of Maternal-Fetal \& Neonatal Medicine, 13(6), 362-380. https://doi.org/10.1080/jmf.13.6.362.380

Martin, J. A., Hamilton, B. E., Sutton, P. D., Ventura, S. J., Menacker, F., Kimeyer, S., \& Mathews, M. S. (2009). Births: Final data for 2006. National vital statistics reports, 57(7). Hyattsville, MD: National Center for Health Statistics.

Melamed, N., Yogev, Y., Meizner, I., Mashiach, R., Pardo, J., \& Ben-Haroush, A. (2011). Prediction of fetal macrosomia: effect of sonographic fetal weight - estimation model and threshold used. Ultrasound in Obstetrics \& Gynecology, 38(1), 74-81. https://doi.org/10.1002/uog.8930

Reichman, N. E., \& Florio, M. J. (1996). The effects of enriched prenatal care services on Medicaid birth outcomes in New Jersey. Journal of Health Economics, 15(4), 455-476. https://doi.org/10.1016/S0167-6296(96)00491-2

Save the Children. (2013). Surviving the First Day: State of the World's Mothers 2013, ISBN 1-888393-26-2, Retrieved from: http://www.refworld.org/docid/51a5ad654.html

Savona-Ventura, C., \& Chircop, M. (2003). Birthweight influence on the subsequent development of gestational diabetes mellitus. Acta Diabetologica, 40(2), 101-104.

Spencer, N., Bambang, S., Logan, S., \& Gill, L. (1999). Socioeconomic status and birthweight: Comparison of an 
area-based measure with the Registrar General's social class. Journal of Epidemiology and Community Health, 53(8), 495-498. https://doi.org/10.1136/jech.53.8.495

Stevens-Simon, C., \& Orleans, M. (1999). Low-birthweight prevention programs: The enigma of failure. Birth, 26(3), 184-191. https://doi.org/10.1046/j.1523-536x.1999.00184.x

Wilcox, A. J., \& Russell, I. (1983). Birthweight and perinatal mortality: II. On weight-specific mortality. International Journal of Epidemiology, 12(3), 319-325. https://doi.org/10.1093/ije/12.3.319

\section{Copyrights}

Copyright for this article is retained by the author(s), with first publication rights granted to the journal.

This is an open-access article distributed under the terms and conditions of the Creative Commons Attribution license (http://creativecommons.org/licenses/by/4.0/). 